\title{
Four decades of ozonesonde measurements over Antarctica
}

\author{
Susan Solomon, ${ }^{1}$ Robert W. Portmann, ${ }^{1}$ Toru Sasaki, ${ }^{2}$ David J. Hofmann, ${ }^{3}$ \\ and David W. J. Thompson ${ }^{4}$ \\ Received 26 February 2005; revised 14 June 2005; accepted 26 August 2005; published 12 November 2005.
}

[1] Ozonesonde observations from Syowa and the South Pole over more than 40 years are described and intercompared. Observations from the two sites reveal remarkable agreement, supporting and extending the understanding gained from either individually. Both sites exhibit extensive Antarctic ozone losses in a relatively narrow altitude range from about 12 to $24 \mathrm{~km}$ in October, and the data are consistent with temperaturedependent chemistry involving chlorine on polar stratospheric clouds as the cause of the ozone hole. The maximum October ozone losses at higher altitudes near $18 \mathrm{~km}(70 \mathrm{hPa})$ appear to be transported to lower levels near the tropopause on a timescale of a few months, which is likely to affect the timing of the effects of ozone depletion on possible tropospheric climate changes. Both sites also show greater ozone losses in the lowermost stratosphere after the volcanic eruption of Mt. Pinatubo, supporting the view that surface chemistry can be enhanced by volcanic perturbations and that the very deep ozone holes observed in the early 1990s reflected such enhancements. Sparse data from the Syowa station in the early 1980s also suggest that enhanced ozone losses due to the El Chichon eruption may have contributed to the beginning of a measurable ozone hole. Observations at both locations show that some ozone depletion now occurs during much if not all year at lower altitudes near $12-14 \mathrm{~km}$. Correlations between temperature and ozone provide new insights into ozone losses, including its nonlinear character, maximum effectiveness, and utility as a tool to distinguish dynamical effects from chemical processes. These data also show that recent changes in ozone do not yet indicate ozone recovery linked to changing chlorine abundances but provide new tools to probe observations for the first such future signals.

Citation: Solomon, S., R. W. Portmann, T. Sasaki, D. J. Hofmann, and D. W. J. Thompson (2005), Four decades of ozonesonde measurements over Antarctica, J. Geophys. Res., 110, D21311, doi:10.1029/2005JD005917.

\section{Introduction}

[2] The stratospheric ozone layer plays a vital role in the earth system through its absorption of ultraviolet light from the Sun. While scientific interest in ozone began more than a century ago, its systematic global monitoring at sites worldwide traces to the International Geophysical Year in 1957-1958, an international effort that also helped foster construction and year-round use of Antarctic research stations beginning in the late 1950s and early 1960s.

[3] Among the fledgling observational records begun at that time were measurements not only of meteorological parameters, such as temperature, pressure, and wind, but also of ozone. Three stations in Antarctica have archived

\footnotetext{
${ }^{1}$ NOAA Aeronomy Laboratory, Boulder, Colorado, USA.

${ }^{2}$ Japan Meteorological Agency, Tokyo, Japan.

${ }^{3}$ NOAA Climate Monitoring and Diagnostics Laboratory, Boulder, Colorado, USA.

${ }^{4}$ Atmospheric Science Department, Colorado State University, Fort Collins, Colorado, USA.
}

Copyright 2005 by the American Geophysical Union. 0148-0227/05/2005JD005917\$09.00 nearly continuous daily measurements of the total integrated ozone column since at least the 1960s: the British station at Halley, the Japanese station at Syowa, and the American station at the South Pole (see Figure 1). Records of the vertical profile of ozone as measured by balloons on a weekly or bimonthly basis began in the 1960s at just two stations still measuring today, Syowa and the South Pole (see Table 1). Only the Syowa data cover the period from 1973 to 1985 , making that ozonesonde record unique in its vertically resolved coverage of the Antarctic ozone layer during a critical era in its evolution.

[4] In the mid-1970s, public and scientific interest in ozone intensified because of the recognition that anthropogenic chlorine and bromine compounds, (particularly chlorofluorcarbons, CFCs), might alter global exposure to ultraviolet light through ozone depletion (see, e.g., recent reviews by Solomon [1999] and World Meteorological Organization/United Nations Environment Program (WMO/UNEP) [2003]). By the early 1980s, scientific studies suggested that continued use of these industrial chemicals might deplete the total ozone column by a few percent in about a century, with the largest local depletions occurring at high altitudes (about $40 \mathrm{~km}$ above ground level) as a result of gas phase chemical reactions. No studies 


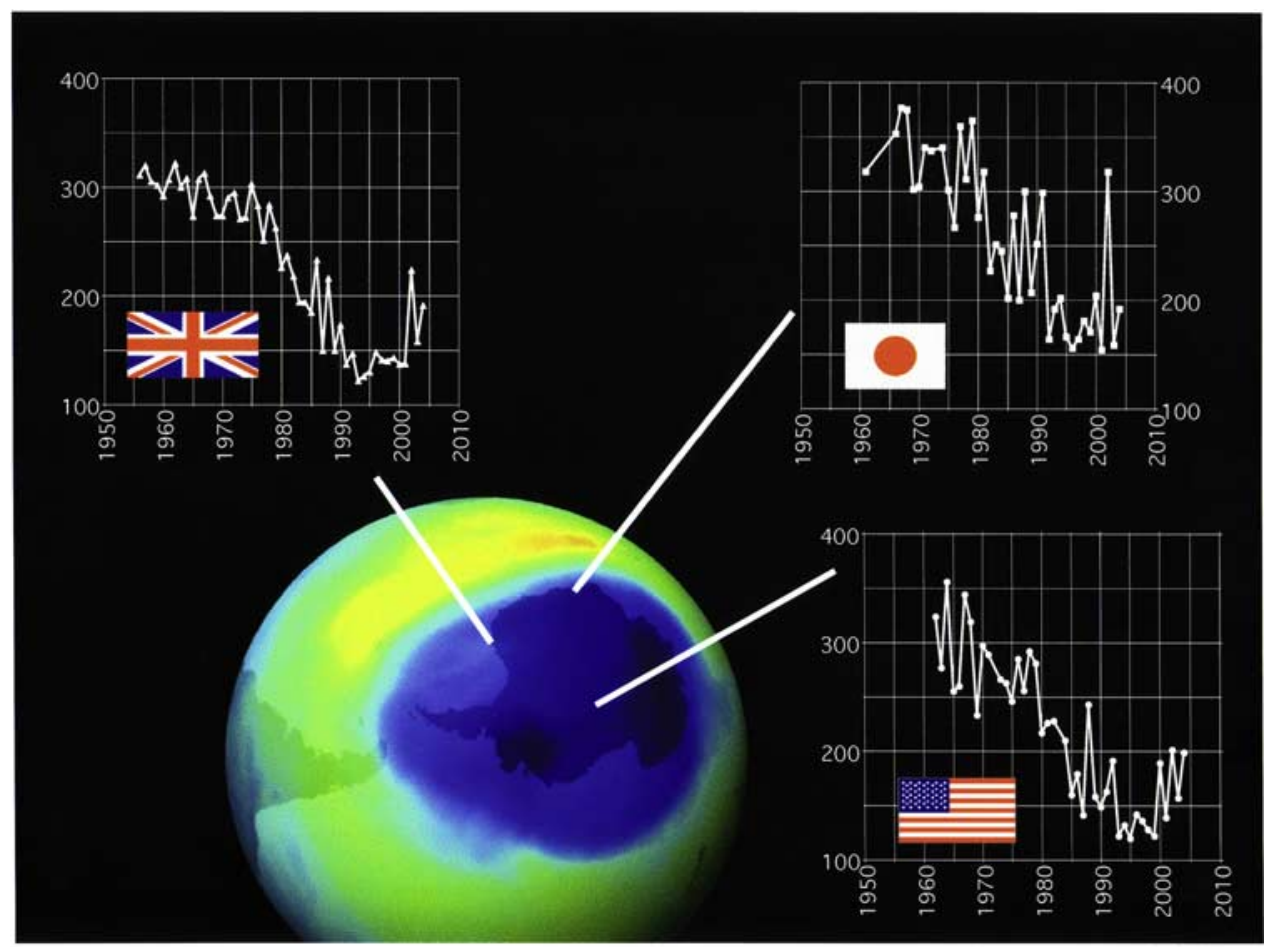

Figure 1. October monthly mean total ozone records (in Dobson Units) from (top left) Halley, (top right) Syowa, and (bottom right) South Pole stations, with the latter being the mean of the second half of the month only, because of the limited availability of sunlight needed to make measurements there. Data for Halley are courtesy of J. D. Shanklin, British Antarctic Survey. A satellite ozone map for 6 September 2000 is also shown (courtesy NASA). The satellite map shows that Syowa is located very close to the edge of the ozone hole on this particular day.

predicted that the Antarctic ozone column losses would be far greater than those in other locations.

[5] In the mid-1980s, an unprecedented change in October Antarctic ozone was documented using both total ozone and ozonesonde instruments [Farman et al., 1985; Chubachi, 1984]: total ozone appeared to be depleted not by a few percent but by about a third, not in the far future but just a few years after projections suggested that little would occur for a century. This dramatic phenomenon was quickly dubbed the "ozone hole," and is illustrated in both ground-based and satellite total column data in Figure 1.

[6] It was suggested that these much larger ozone losses were linked not to the gas phase reaction sequence involving chlorine that operates in the upper stratosphere near $40 \mathrm{~km}$, but to heterogeneous chlorine chemistry (especially the key reaction between $\mathrm{HCl}$ and $\mathrm{ClONO}_{2}$ produced from $\mathrm{CFCs}$ ) on the surfaces of polar stratospheric clouds that form near $20 \mathrm{~km}$ under cold conditions [Solomon et al., 1986]. This change in chemistry from gaseous to heterogeneous processes profoundly changed the nature and magnitude of the ozone depletion issue. Along with the change in understanding from gas phase to key reactions on surfaces, the altitudes of greatest vulnerability shifted to the location where most of the total ozone resides, explaining why the total column changes were so much larger than had previously been thought possible.

[7] Since the discovery of the ozone hole, its nature and character has been probed by a powerful combination of ground-based, balloon-borne, and satellite observations that have comprehensively documented the changes in ozone and other chemicals. While total ozone observations are the cornerstone documenting the historic depletion of the ozone layer, only the ozonesonde records at Syowa and South Pole can reveal the full temporal and vertical structure of the ozone changes from the period before the ozone hole formed to the present. This paper updates, intercompares, and extends earlier findings by Chubachi [1984], Hofmann et al. [1987, 1997], and Iwasaka and Kondoh [1987]. A few data points taken at South Pole and at Hallett in the early 1960s using the less precise Regener chemiluminescent method are also discussed. While excellent ozonesonde observations are available for some years at a few other Antarctic sites, no other observations comprehensively span the decades of observation that are the subject of this work, and more limited records will not be considered here.

[8] We first discuss ozone profiles as measured at the two sites in spring, the time of maximum ozone depletion. The height dependence and extent of the springtime ozone depletion is important for understanding ozone chemistry, and we show a very high degree of consistency in the average profiles observed at these two independent sites. We also present measurements in other seasons, which provide additional information regarding ozone depletion photochemistry as well as dynamical linkages, including possible coupling to surface climate change. We evaluate low-frequency variability apparent in multiple years of data, including the influence of volcanoes. Data obtained since 2001, including the unusual year 2002 (see Figure 1), are 
Table 1. Ozonesondes at Hallett, Syowa, and South Pole by Year and Type

\begin{tabular}{|c|c|c|c|}
\hline Year & $\begin{array}{l}\text { Number of } \\
\text { Sondes Reaching } \\
\text { at Least } 100 \mathrm{hPa}\end{array}$ & Year & $\begin{array}{l}\text { Number of } \\
\text { Sondes Reaching } \\
\text { at Least } 100 \mathrm{hPa}\end{array}$ \\
\hline \multicolumn{4}{|c|}{ Hallett, -72.3,170.2, Regener } \\
\hline 1962 & 14 & & \\
\hline \multicolumn{4}{|l|}{1963} \\
\hline \multicolumn{4}{|c|}{ Syowa, -69,39.6, Electrochemical } \\
\hline 1966 & 12 & 1986 & 6 \\
\hline 1967 & 3 & 1987 & 28 \\
\hline 1968 & 10 & 1988 & 26 \\
\hline 1969 & 9 & 1989 & 25 \\
\hline 1970 & 25 & 1990 & 40 \\
\hline 1971 & 23 & 1991 & 25 \\
\hline 1972 & 19 & 1992 & 40 \\
\hline 1973 & 3 & 1993 & 46 \\
\hline 1974 & 10 & 1994 & 48 \\
\hline 1975 & 6 & 1995 & 43 \\
\hline 1977 & 4 & 1996 & 59 \\
\hline 1978 & 2 & 1997 & 81 \\
\hline 1979 & 2 & 1998 & 65 \\
\hline 1980 & 5 & 2000 & 64 \\
\hline 1981 & 4 & 2001 & 69 \\
\hline 1982 & 36 & 2002 & 54 \\
\hline 1983 & 14 & 2003 & 81 \\
\hline 1984 & 9 & 2004 (to Nov.) & 71 \\
\hline \multicolumn{4}{|c|}{ South Pole, -90, Regener } \\
\hline 1962 & 8 & & \\
\hline 1964 & 40 & & \\
\hline 1965 & 51 & & \\
\hline \multicolumn{4}{|c|}{ South Pole, -90, Electrochemical } \\
\hline 1966 & 8 & 1993 & 68 \\
\hline 1967 & 6 & 1994 & 61 \\
\hline 1968 & 20 & 1995 & 65 \\
\hline 1969 & 3 & 1996 & 73 \\
\hline 1970 & 17 & 1997 & 70 \\
\hline 1971 & 42 & 1998 & 65 \\
\hline 1986 & 46 & 1999 & 69 \\
\hline 1987 & 72 & 2000 & 60 \\
\hline 1988 & 67 & 2001 & 67 \\
\hline 1989 & 55 & 2002 & 61 \\
\hline 1990 & 44 & 2003 & 75 \\
\hline 1991 & 56 & 2004 (to Oct.) & 42 \\
\hline 1992 & 58 & & \\
\hline
\end{tabular}

examined to shed light on causes of recent changes in total column ozone in October. A special focus of this paper is the observed variability (i.e., as revealed by measures such as the range, probability distributions, or the variance of data within a given month) and the temperature dependence of Antarctic ozone. It is shown that these represent important diagnostics for ozone loss that show promise as tools for diagnosing ozone loss and probing the question of detection of ozone recovery (i.e., the degree to which changes in emissions of ozone-depleting source gases such as CFCs are reflected in improvements in the state of the ozone layer [see, e.g., WMO/UNEP, 2003; Reinsel et al., 2005]).

\section{Evolution of Depletion in the Ozone Hole in October}

[9] The depletion of the Antarctic ozone column has been called one of the most remarkable environmental stories of the 20th century. The changes in the October mean total column of ozone since the 1980s as depicted in Figure 1 are indeed dramatic, displaying as much as about two thirds depletion in some years and typically about $50 \%$. However, the local depletions are much larger, and their confinement to a limited range of altitudes attests to the strongly heightdependent nature of the surface chemistry that drives the depletion process. In this section, we focus upon measurements for October, the month when depletion reaches its maximum depth and breadth.

[10] As an example of the approach to be followed in this paper in evaluating the changes in the ozone profile, Figure 2 shows all of the October ozonesonde measurements at the South Pole and Syowa in the late 1960s and early 1970 s versus those of the period from 1990-2000. Averaging over different years could lead to some differences in the details of the shapes of these profiles, but the general features are robust as will be discussed below.

[11] The red lines in Figure 2 show averages of the clearly very different October electrochemical ozone profiles of the historical data versus those of the 1990s, along with their two-sigma standard deviations.

[12] Figure 2 shows the ozone hole to be a localized phenomenon that extends from about 250 to $20 \mathrm{hPa}$ (12 to $24 \mathrm{~km}$ ), with extensive October ozone removal evident at altitudes where the ozone maximum once occurred (100$50 \mathrm{hPa}$, or about $15-20 \mathrm{~km}$ ) but no longer does. The time dependence of October ozone losses in the heart of the ozone depletion layer at $70 \mathrm{hPa}$ (about $18 \mathrm{~km}$ ) is shown in Figure 3 for both the South Pole and Syowa station records. Historic observations taken using Regener ozonesondes at South Pole in the early 1960s are also shown for comparison here, as are those from Hallett station (a site whose latitude is close to that of Syowa although it is at a different longitude, see Table 1). Because the ozone depletion is so extensive in the heart of the depletion layer, the Regener data are useful for examining some aspects of these changes in spite of their greater uncertainties. Examination of such time series data aids the understanding of (1) the trends in mean values, (2) any low-frequency variability that may be present, and (3) changes in the sounding-to-sounding highfrequency variance. Figure 3 shows that all three of these factors are of interest in interpreting the measurements.

[13] The mean values indicated by the lines in Figure 3 (particularly for Syowa with its more complete record) show that the ozone depletion at this most vulnerable altitude developed quickly. No ozone loss was evident in the 1970s although the concentrations of the halocarbon source gases had already begun to increase then [WMO/UNEP, 2003]. Ozone depletion first became apparent in the early 1980s and deepened rapidly during the next decade as shown in Figure 1. From one year to another, South Pole and Syowa generally display linked changes in the mean October depletions at 70 mbar; i.e., years with greater (lesser) mean ozone depletion at Syowa also exhibit greater (lesser) mean depletion at South Pole, as evidence by the lines showing the monthly averaged values for each station (Figure 3 ). The strong correlation between the October monthly mean data at the two sites in Figure 3 is reflected in a value of $r^{2}$ of 0.74 .

[14] High mean values of October ozone obtained in 2002 reflect very unusual meteorological conditions of that particular year, a year in which the winter season stratospheric 


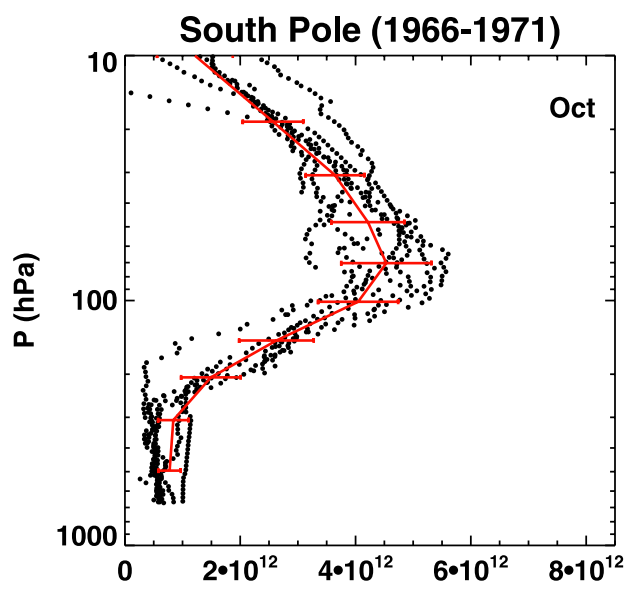

South Pole (1990-2000)
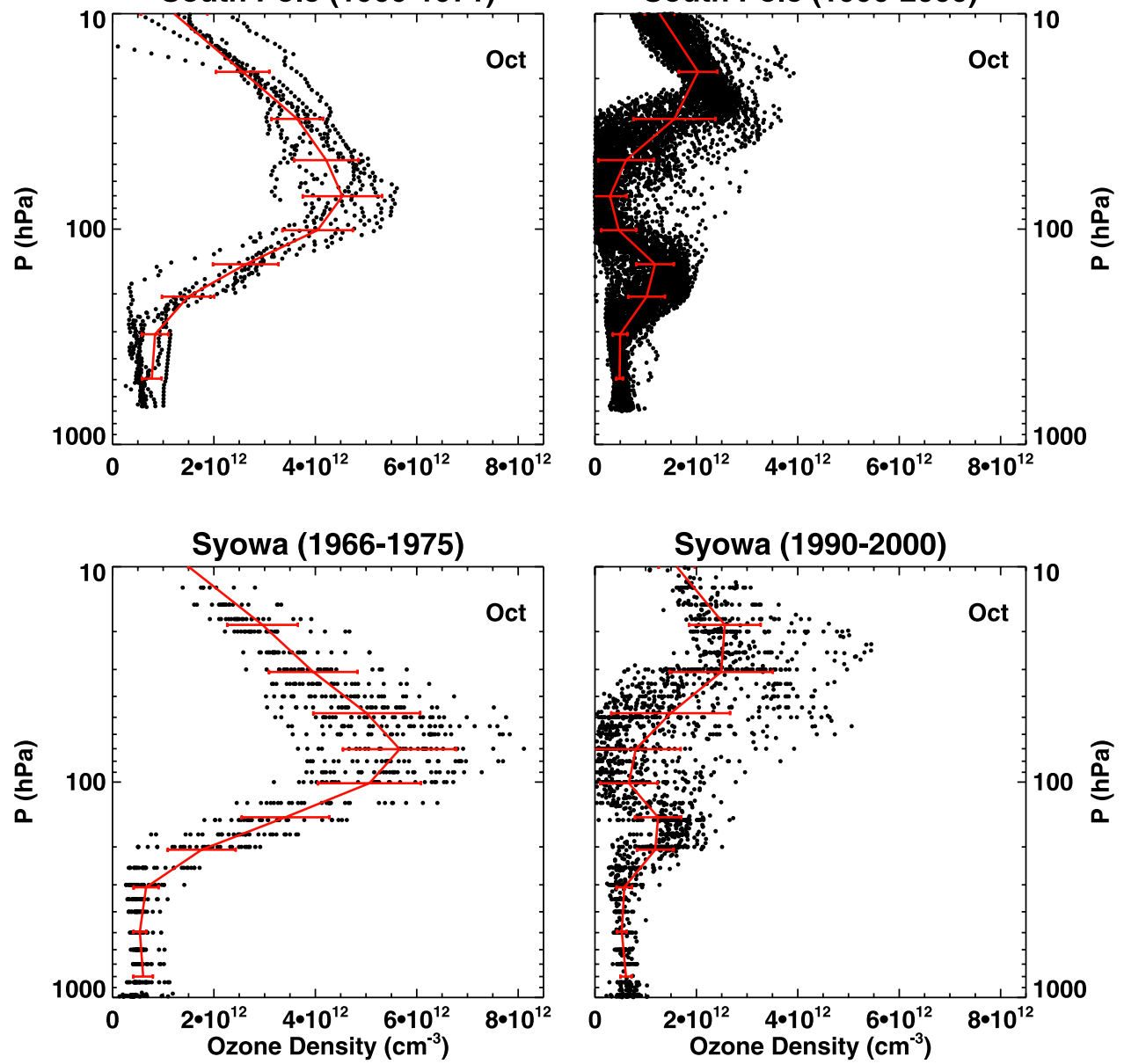

Figure 2. (left) Observations of the available ozone profiles measured in October by electrochemical sondes at the South Pole and Syowa from the 1960s to mid-1970s versus (right) those obtained from 1990 to 2000. Red lines denote the mean profiles, and error bars show the two-sigma standard deviations of these measurements.

polar vortex split in two before the final warming, which was an unprecedented event since systematic Antarctic meteorological observations began in the late 1950s, [e.g., Sinnhuber et al., 2003; Hoppel et al., 2003; Roscoe et al., 2005; Thompson et al., 2005].

[15] Figure 3 shows that large changes are apparent not only in the mean ozone abundances at $70 \mathrm{hPa}$ (solid lines), but also in their variance within a given month. The data display relatively little sounding-to-sounding variability in the $1960 \mathrm{~s}-1970 \mathrm{~s}$. The greatly increasing variability over time suggests an increasingly inhomogeneous distribution, with some air parcels displaying limited depletion while others exhibit nearly complete removal of the local ozone; the heavily depleted air is particularly apparent at South Pole. The logarithmic scale used in Figure 3 is important to show the changes in variability that occur when ozone depletion becomes very severe, as these would be difficult to distinguish on a linear plot as values approach zero. Logarithmic scales are used where necessary to show this throughout this paper.

[16] The data show that around the late 1990s some ozonesondes displayed local abundances at or below the typical instrument detection limit of about 0.004 ppmv, values never before observed and which correspond to greater than $99 \%$ ozone removal. It is noteworthy that such low values have, however, not been observed in 20012004, a point discussed further below.

[17] Figure 4 shows the probability distribution of the ozone measurements at $70 \mathrm{hPa}$ at Syowa and the South Pole using the data shown in Figure 3. This illustrates quantitatively how ozone depletion has not only decreased the mean values of ozone but has also increased their variance, i.e., widened the probability distributions at both sites. At the South Pole the variability in the late 1990s also differs from the period from 2001-2004 (with or without inclusion of 2002). At Syowa, the variance of the data in the 1990s is closer to that of the period since 2001 .

[18] Figure 5 is a scatterplot of the ozone data presented in Figure 4 versus the simultaneously measured local temperature. Changes in temperature from one sonding to another reflect in part the position of the station relative to the polar vortex due to atmospheric wave activity, so that temperatures are indicative of station position relative to the cold vortex. Note that Figure 5 shows that October 70 mbar temperatures measured on historical ozonesondes in the $1960 \mathrm{~s}$ and $1970 \mathrm{~s}$ ranged from about $-80^{\circ} \mathrm{C}$ to near $-40^{\circ} \mathrm{C}$, showing the large influence of such waves. Some recent observations display even lower temperatures below 


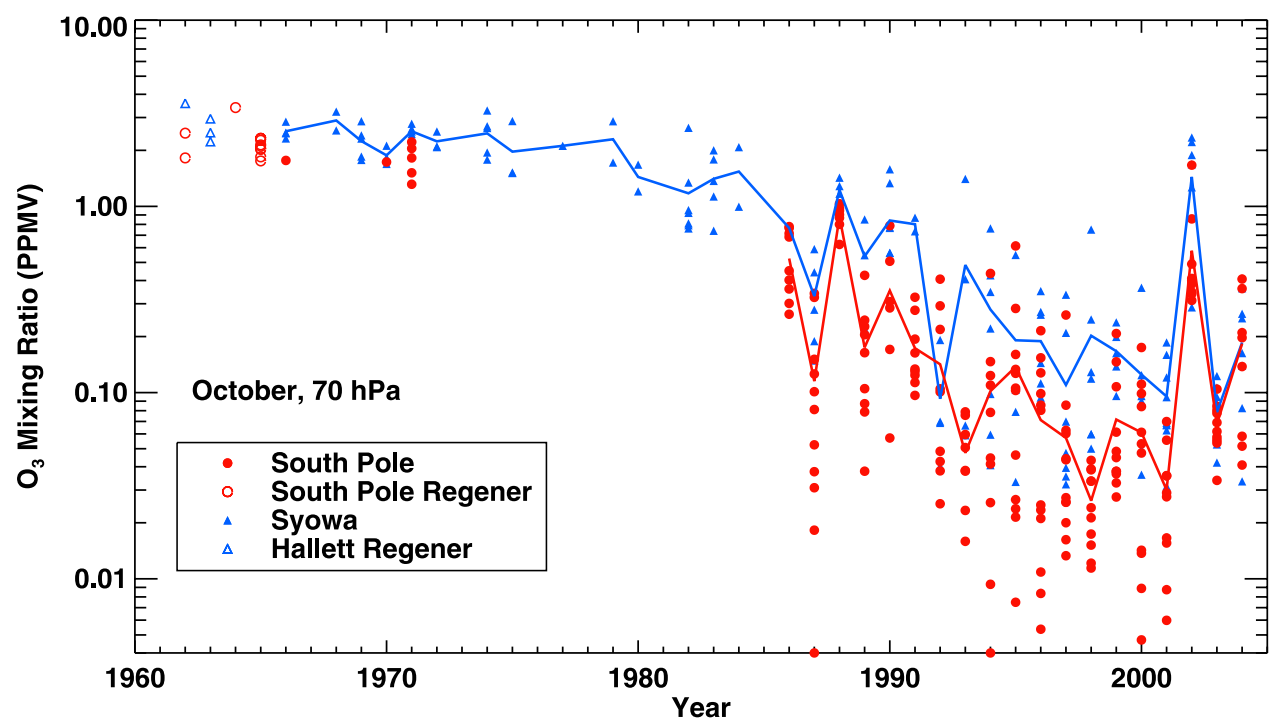

Figure 3. Observations of ozone mixing ratios at $70 \mathrm{hPa}$ (about $18 \mathrm{~km}$ ) over Antarctica in October since the $1960 \mathrm{~s}$ for those points above $0.004 \mathrm{ppmv}$ (believed to represent the approximate instrument detection limit). The electrochemical measurements from South Pole and Syowa stations are shown as red and blue solid circles and triangles, and the colored lines show the monthly means. Regener data obtained in the early 1960s from South Pole and Hallett stations are depicted as red and blue open circles and triangles, respectively.

$-85^{\circ} \mathrm{C}$. These are likely linked to cooling trends due to feedback from the extensive ozone losses concurrently observed [e.g., Newman and Randel, 1988]. We emphasize that the temperatures observed during the soundings repre- sent only the local values at that time, while the chemical ozone losses are expected to depend upon the full history of spring season temperatures experienced in any given air parcel. Even rather small fluctuations in temperature due,
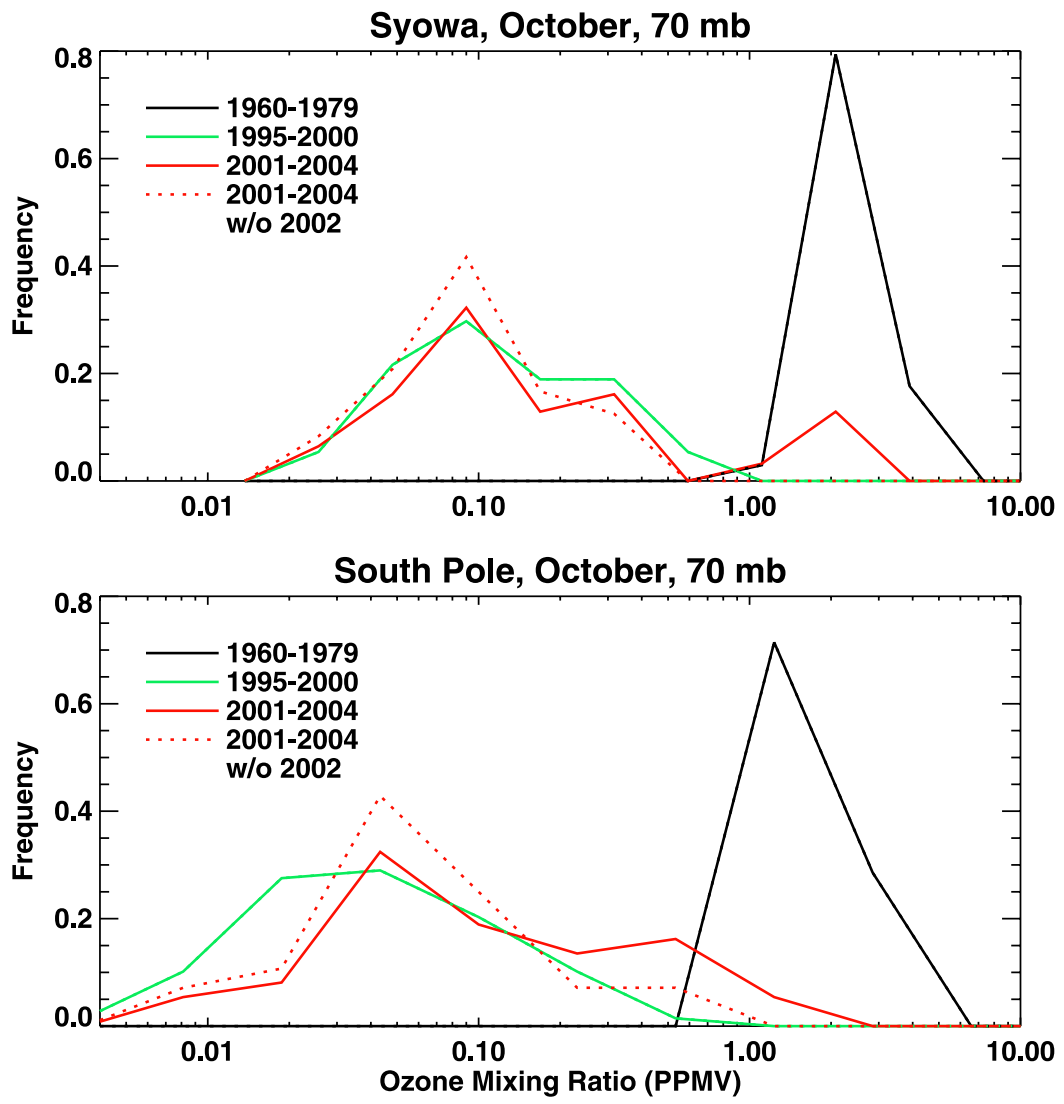

Figure 4. Frequency distributions of $70 \mathrm{hPa}$ measurements of ozone at Syowa and at the South Pole for different periods. 


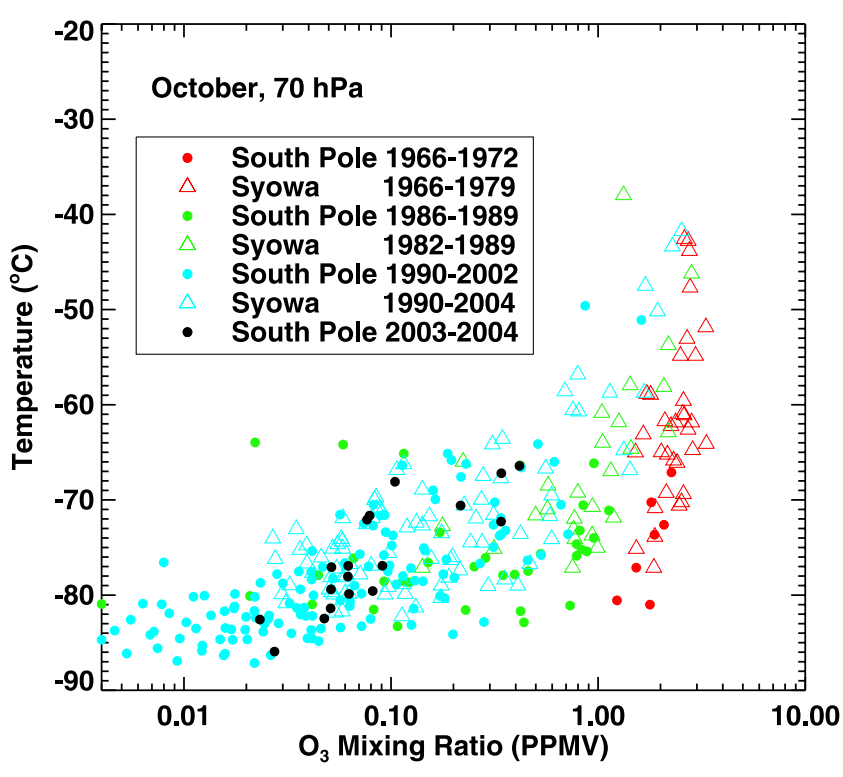

Figure 5. Scatterplot of October $70 \mathrm{hPa}$ ozone mixing ratios with temperatures measured by ozonesondes at South Pole and Syowa for different groupings of years. Red triangles and circles denote historical data as available at each station in the 1960 s and 1970 s, while green points show data in the 1980s and light blue shows data post-1990 with the exception of 2003-2004 at the South Pole in black.

for example, to gravity waves, can have substantial effects on the rate of ozone depletion through heterogeneous chemistry at cold temperatures [Carslaw et al., 1998]. It should also be noted that the ozonesonde sampling is infrequent, with fewer than 10 soundings being taken per month, often as few as 4 . In spite of these limitations, Figure 5 shows that the observed October ozone at this pressure level is closely correlated to the observed temperature, and that this linkage has changed with time as the ozone hole developed. The historical observations from the 1960s and early 1970s shown in red for both Syowa and the South Pole reveal only a weak dependence on temperature in spite of large temperature changes. Thus polar ozone was clearly quite homogeneous irrespective of the local temperatures prior to the onset of ozone hole chemistry. In the 1980s and 1990s, ozone began to show a marked and variable dependence on temperature, with the largest depletions occurring nonlinearly in association with the coldest temperatures. Not all cold points show the same ozone losses, probably reflecting factors such as the range not just of the instantaneous temperatures on the sounding but also their past history as well as the history of air parcel illumination that is also essential for ozone depletion photochemistry. As the ozone hole developed, ozone gradients became steeper, so that variations in atmospheric mixing should also be expected to contribute to variability and to the changes in the slope of the ozone-temperature mixing line. Thus the ozone-temperature dependence reflects chemical depletion combined with transport processes and feedbacks.

[19] Figures 3-5 suggest two new diagnostics for ozone recovery. One of these is multiple years when the dependence of ozone upon temperature begins to systematically differ from that obtained in the 1990 s, i.e., to resemble the 1980s (scatterplot as in Figure 5). Figures 3 and 4 show that a second diagnostic of changes not just in the mean but also in the variance, especially the minima, would be a particularly useful way to distinguish the recovery from ozone chemical losses. These measures complement but are not intended to replace other approaches such as trajectory analyses.

[20] Figures 3-5 suggest that the somewhat higher ozone values observed at South Pole in 2003 and 2004 reflect warmer average temperatures in these years at that location (but note that warmer temperatures were not observed in those years at Syowa, so that the behavior of ozone there is different, see Figure 13). In particular, Figure 5 shows that the data from South Pole in recent years at 70 mbar are not outside the range in observed ozone-temperature correlation of other years and hence do not suggest that recovery is already occurring. Examination of the ozone-temperature scatterplots for restricted periods such as the late September or early October (not shown) as well as for other pressure levels supports this conclusion (see Figures 7, 8, 13, and 14).

[21] Figure 6 shows how the averaged October mean ozone profiles at Syowa and at the South Pole have evolved over decades. Examination of profile information such as that of Figure 6 has played a key role in the identification of heterogeneous chemistry on cold polar stratospheric clouds as the primary cause of the ozone depletion mechanism since the discovery of the ozone hole as noted earlier. For the purpose of comparison of the general behavior of the depletion that is the focus of this section, we compare the average profiles of the electrochemical sondes obtained in the 1960 s and 1970s at each station to those averaged over later periods of available data in the 1980s and 1990s (note that available years differ between the two stations in the 1980s). Figure 6 shows that the region of October ozone depletion is very sharply delineated at both sites, ranging from near $250 \mathrm{hPa}$ or about $12 \mathrm{~km}$ to $30 \mathrm{hPa}$, about $24 \mathrm{~km}$, supporting and extending the view that it is largely driven by the height dependence of the chemistry involved. While the error bars in Figure 6 may appear to be large, they represent two standard deviations of the data and should be interpreted with the aid of Figures 3-5. The change in the size of the error bars in the profiles of Figure 6 does not reflect random errors but rather the large changes in ozone variability which are linked to temperature as already shown. These considerations imply a need for caution in interpreting error bars in studies of the ozone hole.

[22] The general similarity obtained in the October ozone depletion profiles illustrates that the ozone losses cover a vast region extending from close to the heart of the polar vortex typically near the South Pole to at least its edges near Syowa, a distance of over $3000 \mathrm{~km}$. Syowa displays somewhat smaller October mean ozone depletion and warmer temperatures (see Figure 5) in the heart of the depletion layer near 50 to $100 \mathrm{hPa}$ as compared to South Pole.

\section{Ozone Changes Throughout the Annual Cycle}

[23] In this section, we discuss the changes in ozone observed at several different pressure levels at Syowa and 

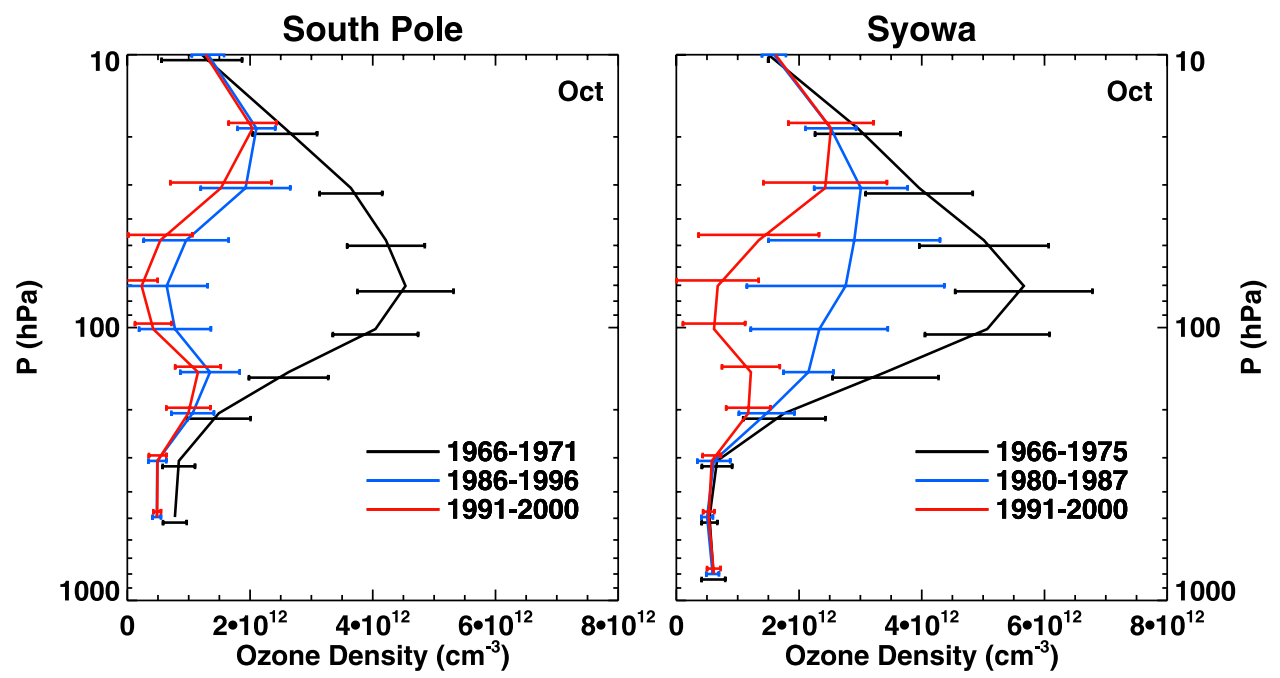

Figure 6. (left) Observations of the October average ozone profiles measured at the South Pole in three different periods versus (right) those obtained at Syowa. Note that different years of observations are available in the 1960s, 1970s, and 1980s for the two sites.

South Pole throughout all the months of the year. While the ozone depletion is greatest on average in October, it begins earlier in the winter/spring season, depending upon the exposure of cold air parcels to sunlight [e.g., Sanders et al., 1993; Roscoe et al., 1997; Lee et al., 2000]. Figures 7 and 8 show how the ozone abundances vary seasonally and over the decades at 70 and 150 mbar, respectively, at Syowa and South Pole. The contrast in ozone behavior particularly in September and October between data taken in the 1960s1970 s, versus the $1980 \mathrm{~s}, 1990 \mathrm{~s}$, and $2000 \mathrm{~s}$ is striking, illustrating the rapid seasonal depletion occurring deep in the vortex in spring [see, e.g., Farman et al., 1985; Bevilacqua et al., 1997].

[24] Figure 7 shows that there is little or no ozone depletion at 70 mbar (near $18 \mathrm{~km}$ ) in the heart of the depletion region in winter at the South Pole, and that ozone loss begins abruptly in September there. Depletion at this altitude starts significantly earlier at Syowa $\left(69^{\circ} \mathrm{S}\right)$, because of earlier exposure to sunlight at this lower-latitude station [see Lee et al., 2000; Bevilacqua et al., 1997]. The availability of the full record of historical data in Figure 7 from the 1960s-1970s, and 1980s, allows clear identification of some ozone loss as early as July at Syowa. Figure 7 also shows that some air parcels at South Pole display deeper maximum local depletions (up to $99.98 \%$ ) compared with those at Syowa (around 98.5\%) at this altitude, consistent with the interpretation of the ozone-temperature relationship as shown in Figure 5. Cold temperatures are important not only to deplete ozone in September, but also to maintain low ozone in October through continuing chemical processing [Portmann et al., 1996], and temperatures also reflect key dynamical processes that affect ozone. In particular, ozone depletion recovers rapidly in November as the Antarctic winter vortex at that level typically begins to warm and ultimately to break down because of increased stratospheric wave activity [e.g., Mechoso et al., 1985; Jones and Shanklin, 1995].

[25] Figure 8 shows ozone loss at 150 mbar (near $13 \mathrm{~km}$ ) at both sites as well. Comparison of Figures 7 and 8 shows that the ozone loss occurs later at the lower altitude. The observations from Syowa also suggest progressive development of significant year-round ozone loss from the $1960 \mathrm{~s}-1970 \mathrm{~s}$ to the $1980 \mathrm{~s}$ to the $1990 \mathrm{~s}$ at this altitude, while the ozone loss remains seasonal at South Pole.

[26] Thompson and Solomon [2002] and Gillett and Thompson [2003] have suggested that the extensive depletion of Antarctic ozone and associated changes in circulation within the polar vortex may have links to the observed changes in Antarctic tropospheric climate, including the surface cooling observed over the Antarctic plateau and the warming of the Antarctic peninsula region. While the maximum ozone depletion occurs in October, the propagation of cooling to the surface is delayed several months to December-January. Figure 9 probes the seasonal and vertical structure of the ozone losses that may be linked to these climate changes in detail by showing the observed seasonal changes in ozone at 70,150 , and $200 \mathrm{hPa}$ from electrochemical ozonesondes at the South Pole and Syowa, for the 1990s as compared to $1965-1975$. The number of sondings reaching higher altitudes above $70 \mathrm{hPa}$ is limited in the historical data in winter because of balloon bursts under very cold conditions; improved plastic balloons now routinely reach higher levels. The layer near $200 \mathrm{hPa}$ is typically just above the tropopause. At lower altitudes below $200 \mathrm{hPa}$ the observed changes are small and difficult to distinguish from typical variability.

[27] Figure 9 demonstrates that the ozone depletion at lower stratospheric altitudes near 150 to $200 \mathrm{hPa}$ lags that of the primary ozone loss region at $70 \mathrm{hPa}$ by several months. Figure 10 shows the time series of ozone observed in February at $200 \mathrm{hPa}$ as an example of the behavior observed in the austral summer season in the lowermost stratosphere, just above the tropopause. Substantial trends are quite large and readily observed (see also Figure 8). Thus, while the maximum column and $50-100 \mathrm{hPa}$ ozone depletion is an austral spring phenomenon, this study shows that the peak ozone losses at lower altitudes closer to the tropopause are delayed to the summer season. It is well known that ozone changes near the tropopause are particularly important for 


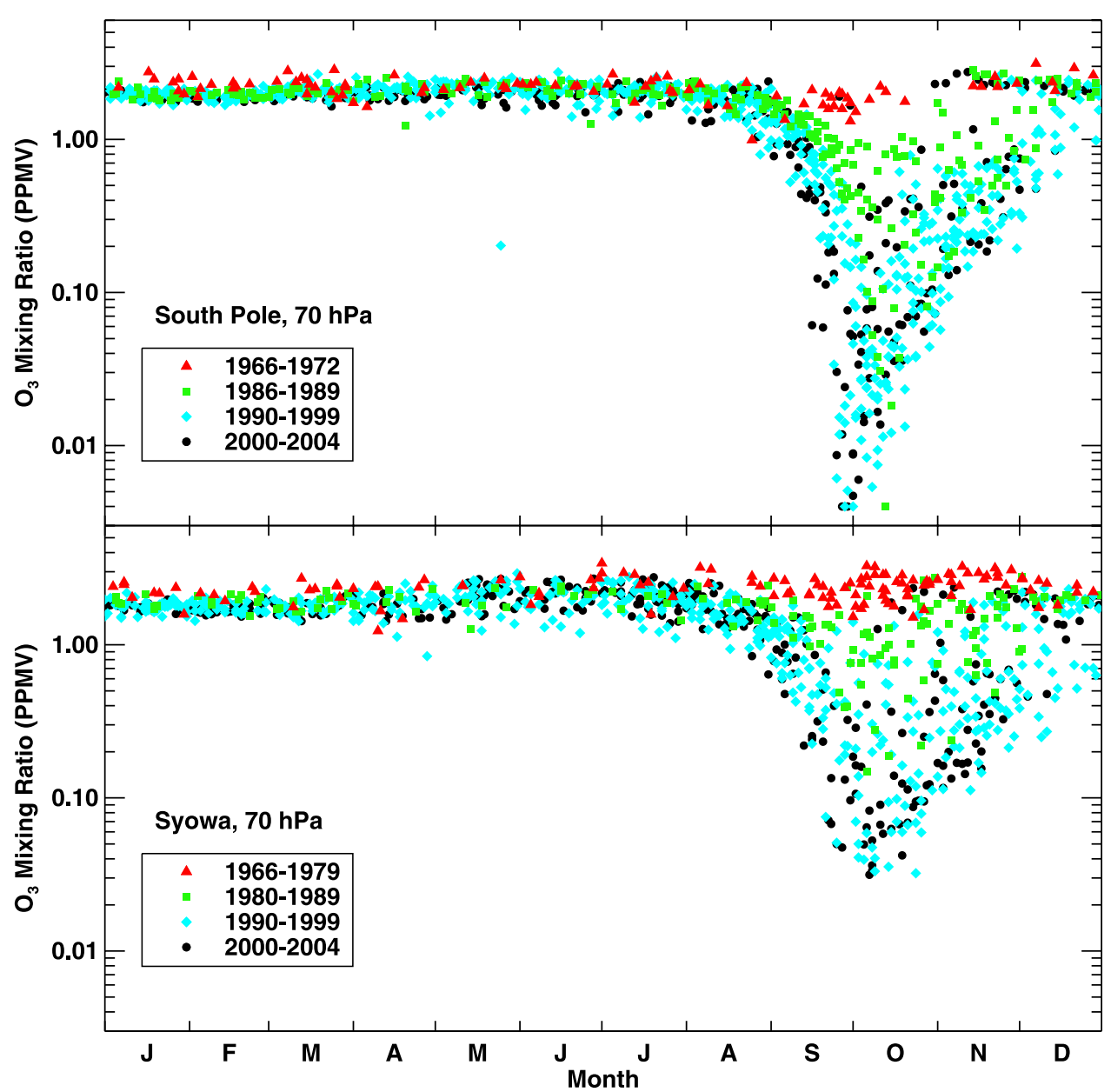

Figure 7. Observations of ozone mixing ratios at $70 \mathrm{hPa}$ (about $18 \mathrm{~km}$ ) over Antarctica throughout the year, for those points above $0.004 \mathrm{ppmv}$ (believed to represent the approximate instrument detection limit). The electrochemical measurements from South Pole and Syowa stations for the 1960s and 1970s are shown as red triangles, while data taken in the 1980s are shown as green squares, those of the 1990s are shown as blue diamonds, and those of the 2000s are shown as black circles.

changes in surface climate [see, e.g., Forster and Shine, 1997].

[28] This lag in ozone losses at lower altitudes is linked at least in part to downward transport of heavily depleted air from above, albeit with considerable dilution in transit. Note for example that Figure 8 shows how ozone increased from October to November at 150 mbar in the 1960s and 1970s, but displays much smaller increases in recent years. This change in character of the seasonal cycle is consistent with downward transport bringing in ozone-rich air prior to the development of the ozone hole, but ozone-poor air in more recent years. Observations of chemical species (including $\mathrm{N}_{2} \mathrm{O}$, or indeed the preozone hole seasonal cycle of total ozone itself) as well as dynamical theory suggest that such transport occurs on a timescale of a few months [see, e.g., Wauben et al., 1997; Solomon, 1999, and references therein]. Further chemical losses may also contribute to the lower-altitude ozone loss, but are beyond the scope of the present paper.

[29] In summary, Figures 7-9 show that while the maximum ozone depletion occurs near $50-100 \mathrm{hPa}$ in October, the ozone depletion just above the tropopause maximizes near December-January, as does the climate change of the Antarctic troposphere [Thompson and Solomon, 2002]. This analysis therefore illustrates why the propagation of circulation anomalies from the Antarctic stratosphere to the troposphere requires a detailed evaluation of the vertical changes in the ozone profile including the complete seasonal cycle of chemistry as well as transport of ozonedepleted air.

\section{Insights From Long-Term Variability: The Role of Volcanoes and Low-Frequency Changes in Temperature}

[30] Ozone abundances throughout the stratosphere display variability from one year to another, or over periods of multiple years, that may be linked to factors including variability in atmospheric transport by the mean circulation, associated changes in temperatures that can affect gas and/ or heterogeneous chemistry, and changes in aerosol abundances due to major volcanic eruptions. Here we examine the ozone records from Syowa and South Pole for multiyear changes that may aid in the interpretation of the extent to 


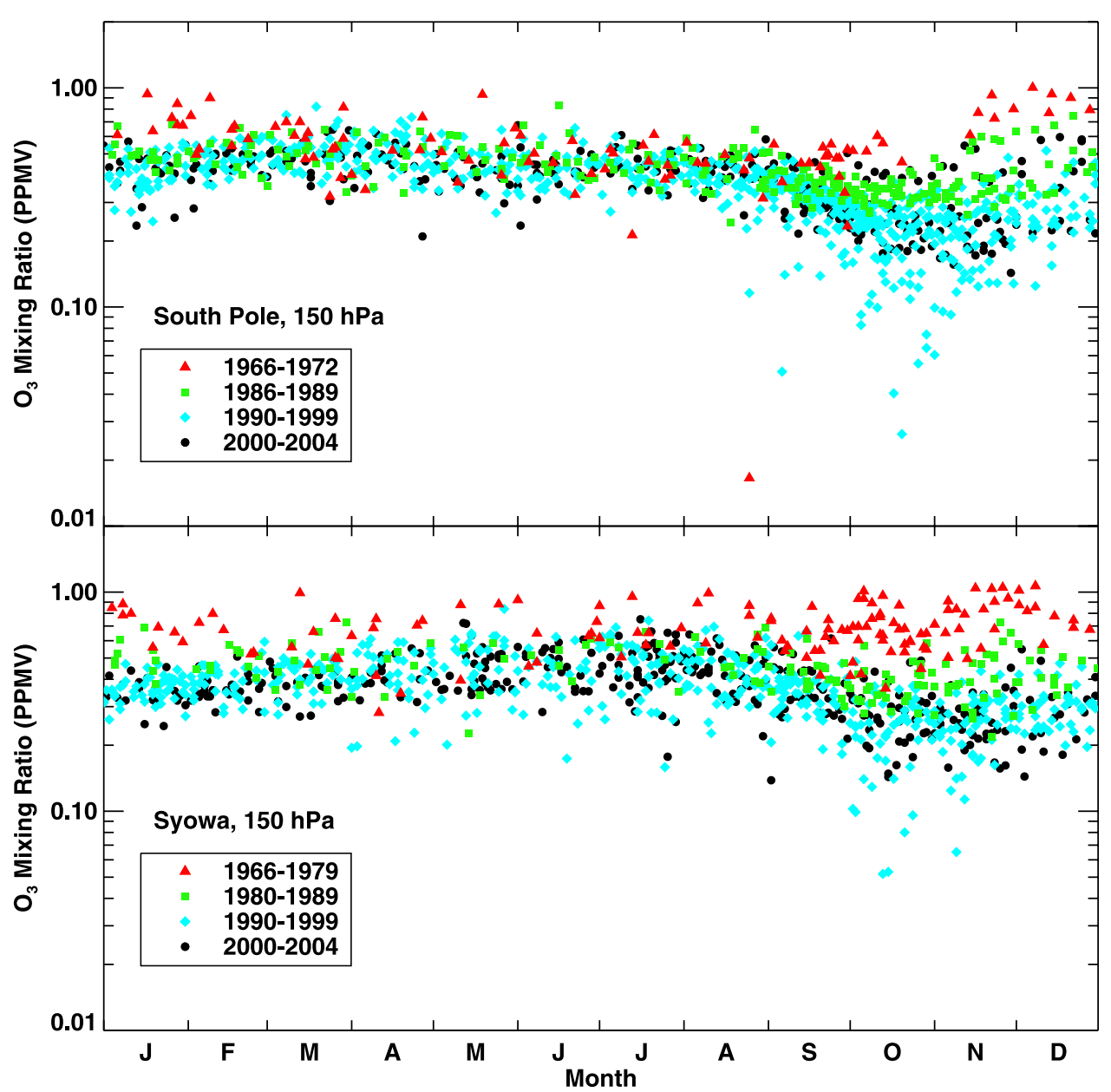

Figure 8. As in Figure 7 but for 150 mbar. The lowest values occur in the years just after the eruption of Mount Pinatubo; see Figure 12.

which such factors affect the temporal variability and structure of Antarctic ozone depletion.

\subsection{Volcanic Effects}

[31] Observations of extinction show that the major eruptions of El Chichon in 1982 and Pinatubo in 1991 led to large increases in particle surface areas in polar regions [e.g., McCormick et al., 1995; Deshler et al., 1992; Adriani et al., 1995]. Hofmann and Oltmans [1993] and Hofmann et al. [1997] suggested that enhanced aerosol surface areas due to the Pinatubo eruption expanded the altitude range of significant Antarctic ozone depletion over several years in the early 1990s into one of its margins, down to lower, warmer altitudes (i.e., 10-14 km) where solid PSCs do not often form. Deshler et al. [1996] and Pitts and Thomason [1993] suggested that volcanic aerosol inputs peaked in 1991 at low altitudes near $11-14 \mathrm{~km}$, but did not penetrate into the Antarctic vortex at higher levels until 1992. Portmann et al. [1996] emphasized the influence of volcanic surfaces in determining both the onset of measurable Antarctic ozone losses in the early 1980s following the El Chichon eruption, and the temporal evolution of measurable total ozone losses.

[32] Figure 11 shows the ozonesonde data in the lowermost stratosphere for Syowa and South Pole in October, updating and extending the findings of Hofmann et al. [1997]. The two records are again in close agreement with one another. It is evident that substantially enhanced ozone losses occurred just after the Pinatubo eruption in the early 1990s at both South Pole and Syowa (see Figure 1 and Hofmann et al.). The influence of the volcanic enhancement of ozone depletion is more readily seen in the profile data than in the total column since it has its largest effect at a limited range of altitudes, making clear that these volcanically enhanced depletions contributed to the particularly low total column ozone abundances measured over much of the Antarctic in the 1990s (compare Figures 11 and 1).

[33] The measurements taken in the earlier years are also of substantial interest. The observations from Syowa station in the early 1980s are extremely important as they are the sole vertically resolved record available at this time, just as the ozone hole first became evident in column measurements. The Syowa data have limited coverage in the early 1980s but are suggestive of enhanced ozone losses in the period just after the eruption of El Chichon, supporting the view that this volcano's effect on chlorine chemistry probably enhanced the ozone losses and contributed to the nonlinear onset of measurable Antarctic ozone depletion. In the next 2-3 years following the El Chichon eruption, 

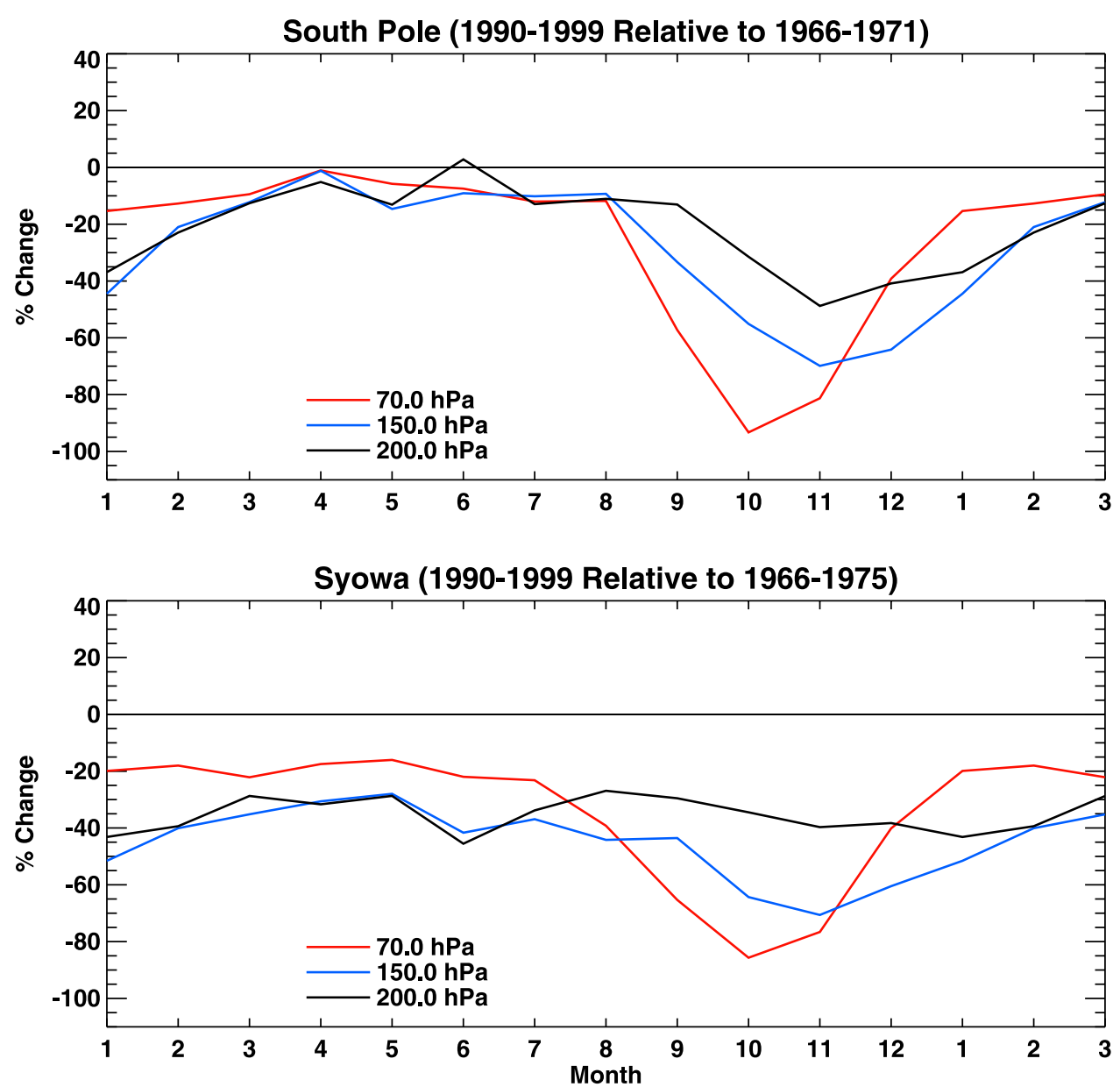

Figure 9. Percent changes in ozone for the 1990s relative to 1966-1975 for (top) South Pole and (bottom) Syowa by month at 70, 150, and $200 \mathrm{hPa}$. The first 3 months of the year are repeated to illustrate the full seasonal cycle.

the Antarctic aerosol abundances measured by satellite decreased as the volcanic aerosols were slowly removed from the stratosphere, but the amount of atmospheric chlorine increased and studies have suggested that the two effects roughly compensated to produce fairly constant ozone values in the late 1980s. By the time of the Pinatubo eruption the stratospheric chlorine content was nearly stable, and the volcanic effects are therefore evident in both the onset and disappearance phases associated with this eruption [Portmann et al., 1996].

[34] The data are sparse in the 1960s but do not suggest comparable effects following the eruption of Mount Agung then, which occurred before the large buildup of anthropogenic contributions to atmospheric chlorine content. Thus Figure 11 provides important support for the view that volcanoes do not deplete ozone in the absence of anthropogenic chlorine. Rather, volcanic surfaces enhance the effectiveness of heterogeneous chemistry just as polar stratospheric cloud surfaces do, leading to greater ozone losses in an atmosphere perturbed by growing additions of anthropogenic chlorine from chlorofluorocarbons in the 1980s and 1990s. Assuming global compliance with the Montreal Protocol and its amendments and adjustments, the abundance of atmospheric chlorine is expected to slowly decay but to remain elevated for at least the next three decades, suggesting that increased Antarctic ozone losses would be expected in any years perturbed by future major volcanic eruptions that enhance the stratospheric aerosol load in this period of vulnerability.

[35] The height dependence of the Pinatubo effect is probed further in Figure 12, where the observations for 1992-1995 are grouped to show their comparison with other periods. Figure 12 further confirms the finding by Hofmann et al. [1997], showing that the enhanced ozone losses are confined to the lower stratosphere, and revealing very close correspondence in the profile of the perturbations at South Pole and Syowa. The localization of these effects at both sites strongly suggests that it is not due to changes in the strength of the mean circulation, which would influence a broad range of altitudes inside the Antarctic vortex. Rather, the observations of depletion at this specific range of altitudes suggest that it is caused by enhanced heterogeneous chemistry due to increases in surface area of the volcanic particulates in regions too warm to form polar stratospheric clouds.

\subsection{Dynamical-Chemical Effects on Multiyear Timescales}

[36] As shown in Figure 1, the total ozone abundances at, for example, South Pole and Syowa in October 2002 were 


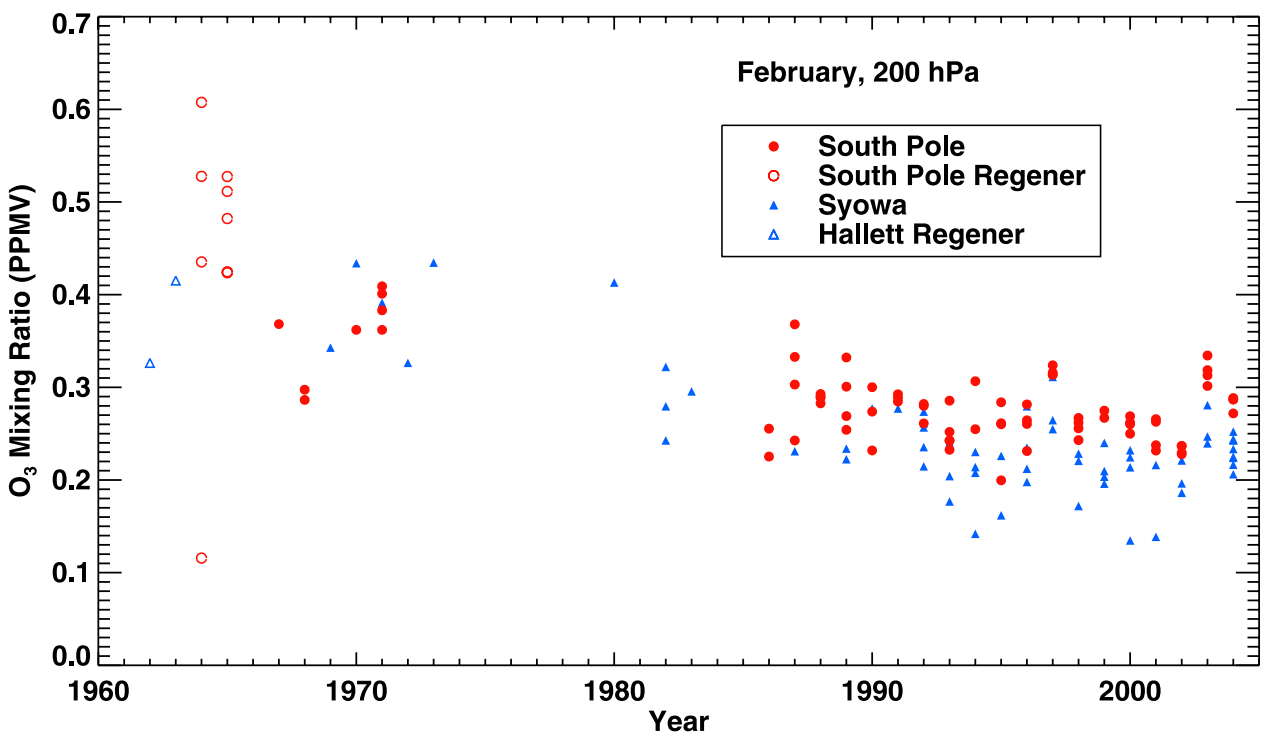

Figure 10. As in Figure 3 but for February at $200 \mathrm{hPa}$. Observations of ozone mixing ratios at $200 \mathrm{hPa}$ (about $13 \mathrm{~km}$ ) over Antarctica in February since the 1960s. The electrochemical measurements from South Pole and Syowa stations are shown as red and blue solid circles and triangles. Regener data obtained in the early 1960s from South Pole and Hallett stations are depicted as red and blue open circles and triangles.
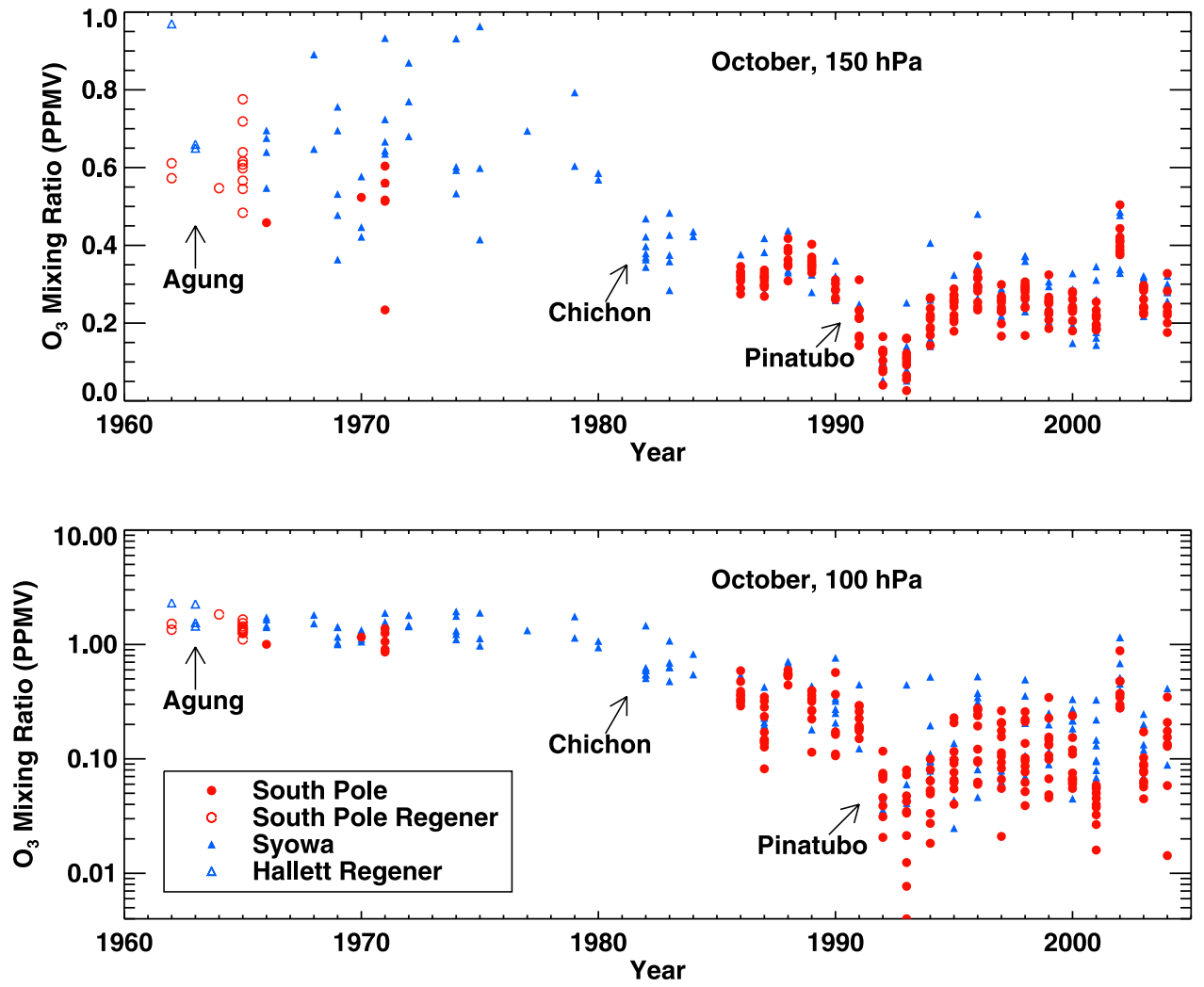

Figure 11. Observations of ozone mixing ratios at 150 and $100 \mathrm{hPa}$ (about 14 and $16 \mathrm{~km}$ ) over Antarctica in October. The electrochemical measurements from South Pole and Syowa stations are shown as red and blue solid circles and triangles. Regener data obtained in the early 1960s from South Pole and Hallett stations are depicted as red and blue open circles and triangles. The years of the known major volcanic eruptions since 1960 are also indicated. 

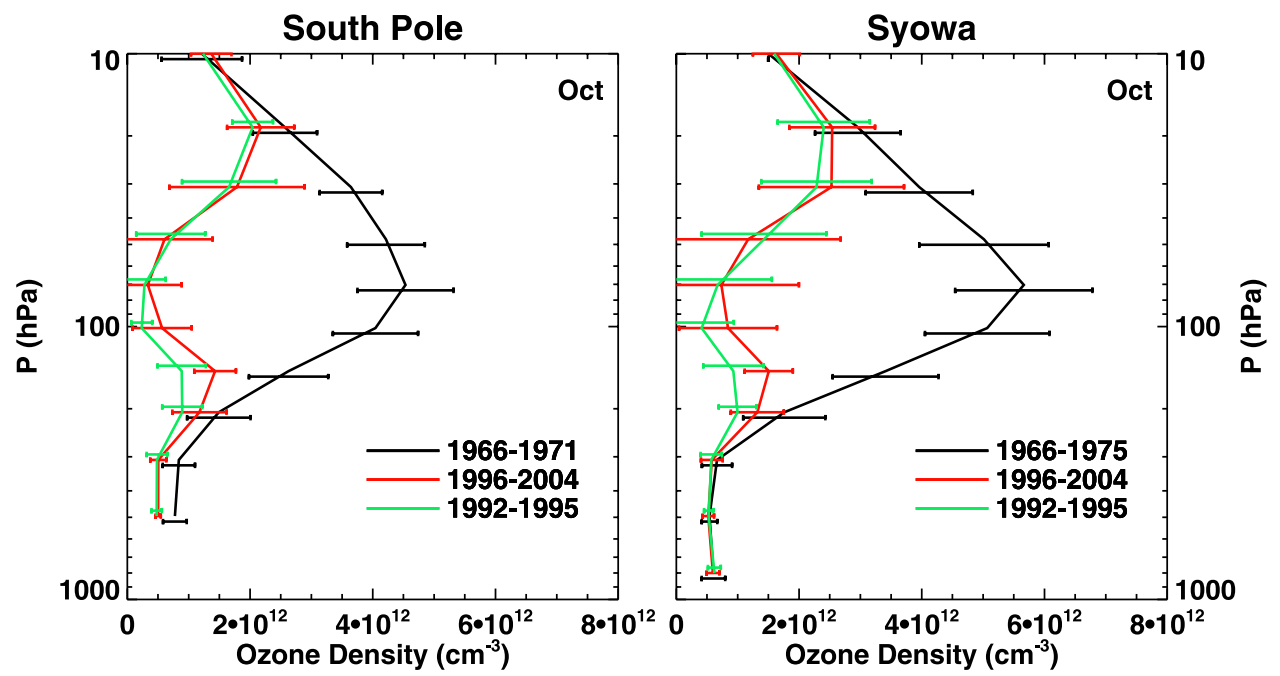

Figure 12. Observations of the October average ozone profiles measured at the South Pole and Syowa in different periods, including the 3-year period 1992-1995 when aerosol abundances were enhanced by the Mt. Pinatubo eruption.

considerably higher than they have been since the ozone hole first appeared. Whether this was a singular event due to natural variability, or the beginning of a systematic change in Antarctic stratospheric meteorology is a matter of current scientific investigation. Some studies have suggested the possibility of linkages between stratospheric dynamics and changing tropospheric climate due to greenhouse warming [e.g., Langematz et al., 2003]. Certainly the observation of the unusual Antarctic ozone hole in 2002 has heightened the importance of gaining a better understanding of polar ozone variability and its linkages to low-frequency dynamical changes, and these are the subject of this section.

[37] Since the 1990s, the maximum October local ozone density and hence largest contribution to the remnant total ozone column typically occurs near $30-20 \mathrm{hPa}$, or about 24-26 km (as shown in Figures 2, 6, and 12), so that very different height levels (and likely different associated processes) now control the October mean total ozone as compared to the period before the ozone depletion began. This important change in the height range that dominates October ozone in the postozone hole era has not been emphasized in previous studies. Here we focus on those altitudes, using the approaches developed above. It is noteworthy that these upper levels are expected to display larger temperature variations associated with waves than lower levels, suggesting that the ozone column in October would be expected to show stronger links to dynamical variability than did the unperturbed ozone of the preozone hole era.

[38] Figure 13 shows observations of ozone (Figure 13, top) and temperature (Figure 13, middle) near the maximum of the remaining ozone at $30 \mathrm{hPa}$ in October for the South Pole and for Syowa. These two panels highlight the interannual changes and show that the late 1990s was significantly colder on average (and the ozone lower) at the South Pole than either the early 1990s or the early 2000s. The coldest years are likely to be linked to reduced stratospheric wave activity and reduced adiabatic heating, while the warmest years are generally those subject to greater planetary wave variability and associated changes in mean circulation.

[39] The coldest years at $30 \mathrm{hPa}$ at the South Pole (especially 1999 and 2000) display not only low monthly mean ozone abundances, but also a larger range as compared to other years, as was noted earlier for lower altitudes (see Figures 3 and 7). Figure 13 (bottom) shows the ozonetemperature correlation at $30 \mathrm{hPa}$ in October at the South Pole, supporting the nonlinear nature of the depletion. Thus this analysis provides evidence that heterogeneous ozone depletion can sometimes reach the $30 \mathrm{hPa}$ level. Greatly reduced local $30 \mathrm{hPa}$ ozone amounts like those seen at the South Pole in for example 1999 in association with occurrences of temperatures below $-80^{\circ} \mathrm{C}$ have not been observed at Syowa. However, this is not surprising since Figure 13 (middle) shows that temperatures at Syowa are generally warmer.

[40] Figure 13 shows that ozone depletion at South Pole not only in 2002 but also in 2001, 2003, and 2004 was less extensive at $30 \mathrm{hPa}$ than in the late 1990s. It further shows that the average temperatures at South Pole were relatively warm at $30 \mathrm{hPa}$ in all of those years compared to those of the late 1990s, and that the ozone abundances observed were comparable to those obtained in the early 1990s for the same average temperatures. Figure 14 presents ozone and temperature profiles averaged for several different sequences of years at the South Pole in October. Figure 14 shows that relatively warm average temperatures and increased ozone abundances compared to the late 1990s were observed throughout the region from 100 to $10 \mathrm{hPa}$ during these measurements, with or without the inclusion of 2002. Thus Figures 13 and 14 show that the higher total ozone abundances obtained at the South Pole in the past few years (see Figure 1) are not necessarily indicative of chemical recovery, but rather are consistent with dynamical variability at that station. Figures 3, 4, and 13 show that Syowa station has not experienced the same low-frequency changes from the late 1990s to the present (nor were the temperatures as cold at Syowa in the 1990s, see Figure 13 

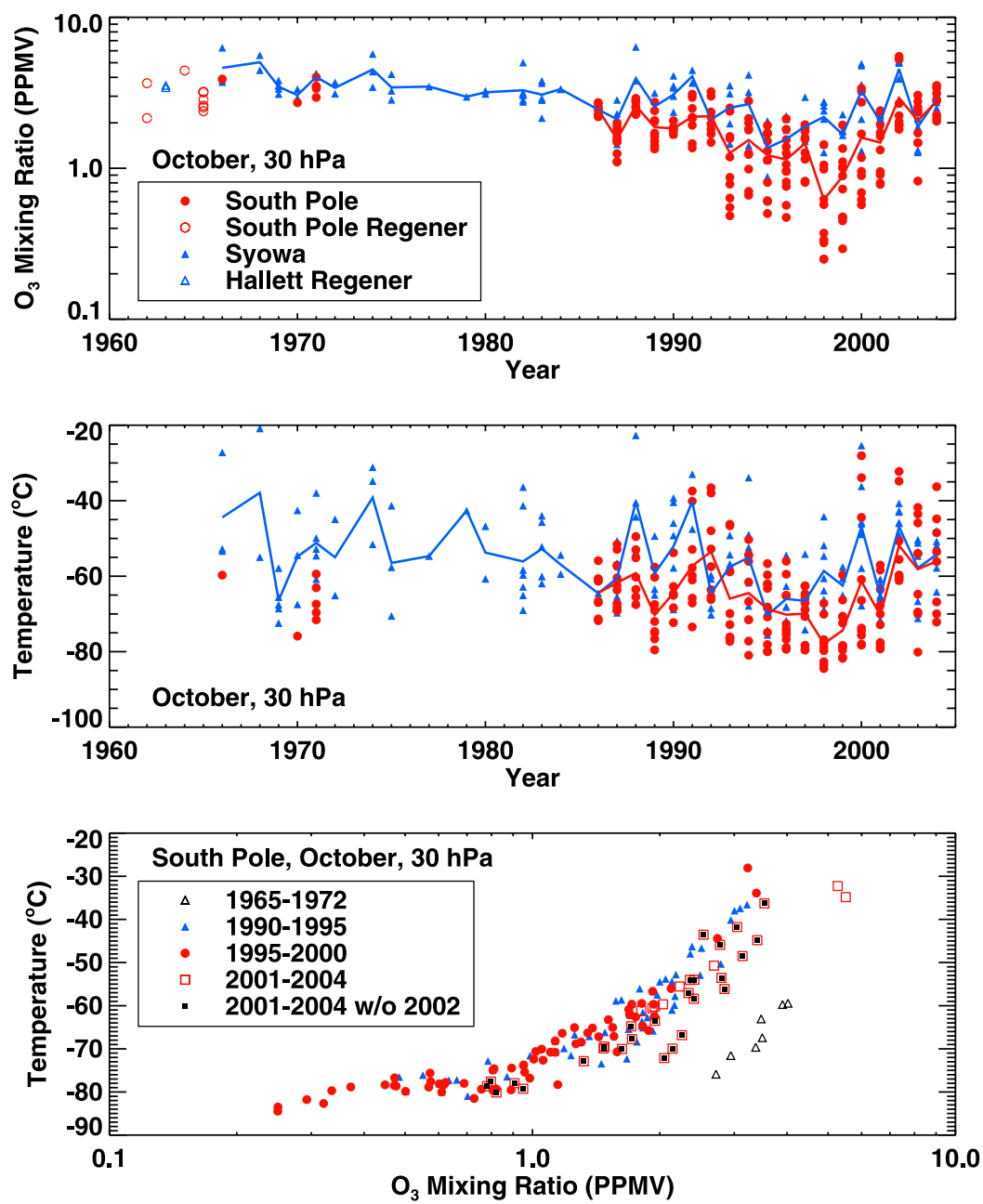

Figure 13. (top) Ozonesonde measurements at $30 \mathrm{hPa}$ in October and (middle) their associated local temperatures. Individual data from Syowa and South Pole are shown as colored points, while the monthly means of these data are shown as solid lines. (bottom) Scatterplot of ozone and temperature obtained from this data for the South Pole in certain periods.

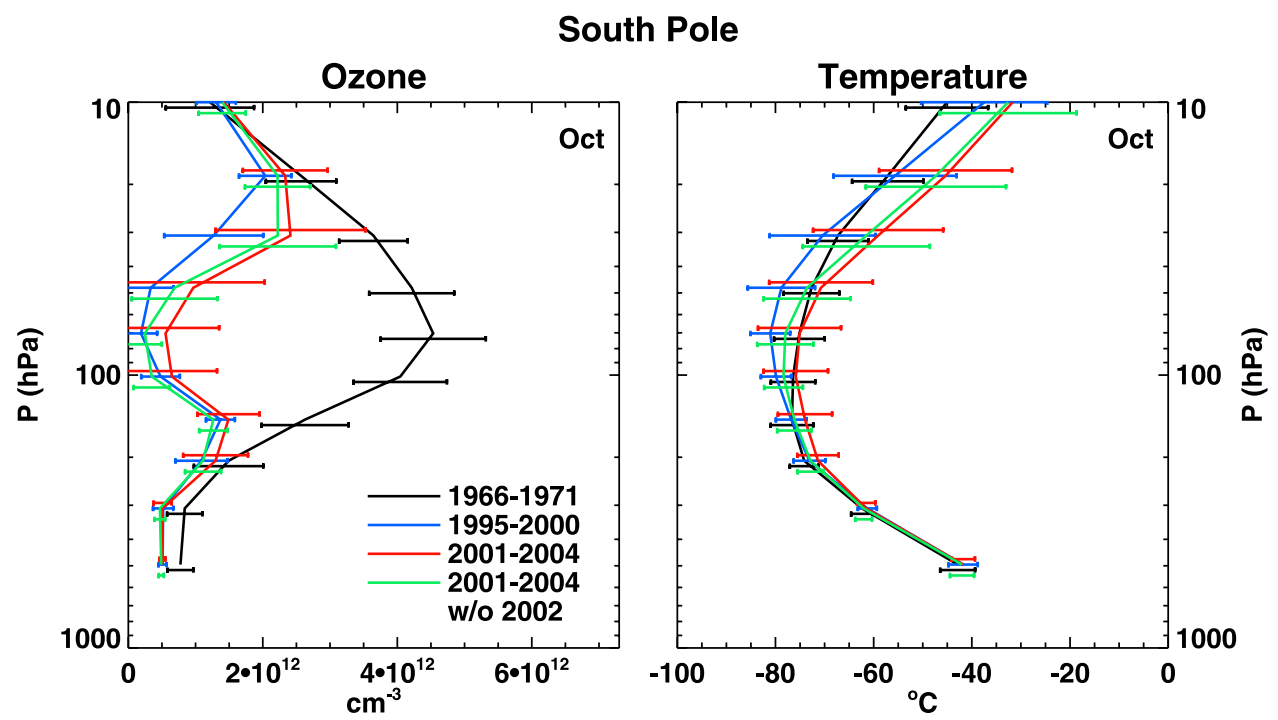

Figure 14. October (left) ozone and (right) temperature sondings at the South Pole for several different groupings of years. The red lines show data for 2001-2004 with 2002, while 2002 has been excluded in the green lines. 
(middle)), further supporting dynamic variability at South Pole as the cause of these changes.

\section{Concluding Summary}

[41] Ozonesondes have documented the vertical structure of the ozone layer over Antarctica for more than 40 years at South Pole and Syowa stations. Both stations show profound depletion in October and lesser but substantial depletion in September, in association with the ozone hole. Depletion is most pronounced between about 250 and $20 \mathrm{hPa}$ at both stations in October, with maximum local ozone losses near $70 \mathrm{hPa}$ that can exceed $98 \%$ depletion compared to the period from the early 1960 s to early 1970 s. These represent the altitudes where temperature-dependent polar stratospheric chemistry involving chlorine is most effective at depleting ozone, and the observations shown here further support the view revealed by many previous studies that this chemistry extends over the entire continent, spanning thousands of kilometers in scale.

[42] The data from both Syowa and the South Pole also suggest that ozone-depleted air is transported down to altitudes close to the tropopause on a timescale of a few months, and this downward transport is likely to be important for studies of the mechanisms and timing of possible effects of changes in stratospheric ozone abundances on tropospheric climate. Both sites also show strong evidence for enhanced ozone losses following the volcanic eruption of Mt. Pinatubo at lower warmer altitudes where the effectiveness of solid polar stratospheric cloud chemistry is reduced (i.e., 200-100 $\mathrm{hPa}$ ). The observations from Syowa are sparse in the early 1980s but indicate that the eruption of the El Chichon volcano also enhanced ozone loss, and thereby contributed to the onset of a measurable ozone hole in the early 1980s.

[43] The effects of changes in ozone depletion due to variations in temperature are also apparent from year-toyear and from sounding-to-sounding in the observations at both sites. At the South Pole, reduced October ozone losses were observed because of a series of relatively warm years since 2001, especially at higher levels near $30 \mathrm{hPa}$. While the springtime stratosphere of 2002 was especially warm, and the ozone depletion of that year therefore rather limited, each of 2001, 2003, and 2004 has also been characterized by warmer temperatures and less ozone loss at the South Pole, compared to the late 1990s when exceptionally cold temperatures and extensive ozone loss occurred there. The changes at Syowa have not exhibited as much low-frequency variability in mean temperatures nor in corresponding ozone losses.

[44] Both stations also reveal remarkable changes in sounding-to-sounding variability in association with ozone depletion. These are linked to large and highly nonlinear changes in the correlation of ozone abundances with temperature as the ozone depletion developed over decades. Ozone correlations with temperature have been shown for several pressure levels, and these reveal new insights into the causes and extent of ozone change. While more complex approaches such as trajectory studies are highly valuable, scatter diagrams of ozone versus temperature are a simple means of identifying changes in dynamical conditions that are likely to have influenced ozone, distinct from possible chemical changes. We have also shown that not just the mean ozone changes but also their variance represent useful tools for probing causes of ozone variations, including lowfrequency changes and the search for recovery as chlorofluorocarbon concentrations decay. Among the signals that may be helpful in detecting the first signs of Antarctic ozone recovery in years to come would be a return not just of the mean ozone to higher values, but also of (1) the ozonetemperature relationship in October to the behavior observed earlier for the same values of temperature and of (2) the variance in ozone abundance to the reduced variance observed in historical ozonesondes.

[45] Thus the ozonesonde observations at Syowa and the South Pole provide a powerful database for probing the processes and evolution of ozone depletion, and continuation of these multidecadal records is likely to provide unique insights to future ozone layer recovery.

[46] Acknowledgments. We are deeply grateful to the many scientists, technicians, and Antarctic support personnel who steadfastly launched the ozonesondes at Syowa Station, South Pole, and Hallett stations that are the subject of this work. We thank Sam Oltmans for helpful comments on ozonesonde accuracy and assistance in accessing the South Pole data set. We also thank the reviewers of this paper for constructive comments that have improved the paper.

\section{References}

Adriani, A., T. Deshler, G. Di Donfrancesco, and G. P. Gobbi (1995), Polar stratospheric clouds and volcanic aerosol during spring 1992 over McMurdo Station Antarctica: Lidar and particle counter comparisons, J. Geophys. Res., 100, 25,877-25,897.

Bevilacqua, R. M., et al. (1997), POAM II ozone observations in the Antarctic ozone hole in 1994, 1995, and 1996, J. Geophys. Res., 102, $23,643-23,657$

Carslaw, K. S., et al. (1998), Increased stratospheric ozone depletion due to mountain-induced atmospheric waves, Nature, 391, 675-678.

Chubachi, S. (1984), Preliminary result of ozone observations at Syowa Station from February, 1982 to January, 1983, Mem. Natl. Inst. Polar Res. Jpn., Spec. Issue, 34, 13-20.

Deshler, T., A. Adriani, G. P. Gobbi, D. J. Hofmann, G. Di Donfrancesco, and B. J. Johnson (1992), Volcanic aerosol and ozone depletion within the antarctic polar vortex during the austral spring of 1991, Geophys. Res. Lett., 19, 1819-1822.

Deshler, T., B. J. Johnson, D. J. Hofmann, and B. Nardi (1996), Correlations between ozone loss and volcanic aerosols at altitudes below $14 \mathrm{~km}$ over McMurdo Station, Antarctica, Geophys. Res. Lett., 23, 2931-2934.

Farman, J. C., B. G. Gardiner, and J. D. Shanklin (1985), Large losses of total ozone in Antarctica reveal seasonal $\mathrm{ClO}_{x} / \mathrm{NO}_{x}$ interaction, Nature, 315, 207-210.

Forster, P. M., and K. P. Shine (1997), Radiative forcing and temperature trends from stratospheric ozone changes, J. Geophys. Res., 102, 10,84110,857 .

Gillett, N., and D. W. J. Thompson (2003), Simulation of recent Southern Hemisphere climate change, Science, 302, 273-275.

Hofmann, D. J., and S. J. Oltmans (1993), Anomalous Antarctic ozone during 1992: Evidence for Pinatubo volcanic aerosol effects, J. Geophys. Res., 98, 18,555-18,561.

Hofmann, D. J., J. W. Harder, S. R. Rolf, and J. M. Rosen (1987), Balloonborne observations of the development and vertical structure of the Antarctic ozone hole in 1986, Nature, 326, 59-62.

Hofmann, D. J., S. J. Oltmans, J. M. Harris, B. J. Johnson, and J. A. Lathrop (1997), Ten years of ozonesonde measurements at the south pole: Implications for recovery of springtime antarctic ozone, J. Geophys. Res., 102, 8931-8943.

Hoppel, K., R. Bevilacqua, D. Allen, G. Nedoluha, and C. Randall (2003), POAM III observations of the anomalous 2002 Antarctic ozone hole, Geophys. Res. Lett., 30(7), 1394, doi:10.1029/2003GL016899.

Iwasaka, Y., and K. Kondoh (1987), Depletion of antarctic ozone: Height of ozone loss region and its temporal changes, Geophys. Res. Lett., 14, $87-$ 90.

Jones, A. E., and J. D. Shanklin (1995), Continued decline of total ozone over Halley, Antarctica, since 1985, Nature, 376, 409-411.

Langematz, U., M. Kunze, K. Krueger, K. Labitzke, and G. L. Roff (2003), Thermal and dynamical changes of the stratosphere since 1979 and their 
link to ozone and $\mathrm{CO}_{2}$ changes, J. Geophys. Res., 108(D1), 4027, doi:10.1029/2002JD002069.

Lee, A. M., H. K. Roscoe, and S. Oltmans (2000), Model and measurements show Antarctic ozone loss follows edge of polar night, Geophys. Res. Lett., 27, 3845-3848.

McCormick, M. P., L. W. Thomason, and C. R. Trepte (1995), Atmospheric effects of the Mt. Pinatubo eruption, Nature, 373, 399-404.

Mechoso, C. R., D. L. Hartmann, and J. D. Farrara (1985), Climatology and interannual variability of wave mean-flow interaction in the Southern Hemisphere, J. Atmos. Sci., 42, 2189-2206.

Newman, P. A., and W. J. Randel (1988), Coherent ozone-dynamical changes during the Southern Hemisphere spring, 1979-1986, J. Geophys. Res., 93, 12,585-12,606.

Pitts, M. C., and L. W. Thomason (1993), The impact of the eruptions of Mount Pinatubo and Cerro Hudson on Antarctic aerosol levels during the 1991 austral spring, Geophys. Res. Lett., 20, 2451-2454.

Portmann, R. W., S. Solomon, R. R. Garcia, L. W. Thomason, L. R. Poole, and M. P. McCormick (1996), Role of aerosol variations in anthropogenic ozone depletion in polar regions, J. Geophys. Res., 101, 22,991-23,006.

Reinsel, G. C., A. J. Miller, E. C. Weatherhead, L. E. Flynn, R. M. Nagatani, G. C. Tiao, and D. J. Wuebbles (2005), Trend analysis of total ozone for turnaround and dynamical contributions, J. Geophys. Res., 110, D16306, doi:10.1029/2004JD004662.

Roscoe, H. K., A. E. Jones, and A. M. Lee (1997), Midwinter start to Antarctic ozone depletion: Evidence from observations and models, Science, 278, 93-96.

Roscoe, H. K., J. D. Shanklin, and S. R. Colwell (2005), Has the Antarctic vortex split before 2002?, J. Atmos. Sci., 62, 581-588.

Sanders, R. W., et al. (1993), Visible and near-ultraviolet spectroscopy at McMurdo Station, Antarctica, 9, Observations of OClO from April to October, 1991, J. Geophys. Res., 98, 7219-7228.
Sinnhuber, B. M., M. Weber, A. Amankwah, and J. P. Burrows (2003), Total ozone during the unusual Antarctic winter of 2002, Geophys. Res. Lett., 30(11), 1580, doi:10.1029/2002GL016798.

Solomon, S. (1999), Stratospheric ozone depletion: A review of concepts and history, Rev. Geophys., 37, 275-316.

Solomon, S., R. R. Garcia, F. S. Rowland, and D. J. Wuebbles (1986), On the depletion of Antarctic ozone, Nature, 321, 755-758.

Thompson, D. W. J., and S. Solomon (2002), Interpretation of recent Southern Hemisphere climate change, Science, 296, 895-899.

Thompson, D. W. J., M. P. Baldwin, and S. Solomon (2005), Stratospheretroposphere coupling in the Southern Hemisphere, J. Atmos. Sci., 62, $708-715$.

Wauben, W. M. F., R. Bintanja, P. F. J. van Velthoven, and H. Kelder (1997), On the magnitude of transport out of the Antarctic polar vortex, J. Geophys. Res., 102, 1229-1238.

World Meteorological Organization/United Nations Environment Program (2003), Scientific assessment of ozone depletion: 2002, Global Ozone Res. and Monit. Proj. Rep. 47, 498 pp., Geneva, Switzerland.

D. J. Hofmann, NOAA Climate Monitoring and Diagnostics Laboratory, Boulder, CO 80305, USA

R. W. Portmann and S. Solomon, NOAA Aeronomy Laboratory, Boulder, CO 80305, USA. (ssolomon@al.noaa.gov)

T. Sasaki, Japan Meteorological Agency, Tokyo 100-8122, Japan.

D. W. J. Thompson, Atmospheric Science Department, Colorado State University, Fort Collins, CO 80523-1371, USA. 